\title{
The Effect of Perceived Maternal Acceptance-Rejection on Mental Illness among Orphaned Adolescents in Indonesia
}

\section{Linda Mutiara Larassati Reksodiputro ${ }^{\mathrm{a}}$ and Lia Mawarsari Boediman ${ }^{\mathrm{b}}$}

${ }^{a}$ Faculty of Psychology, Universitas Indonesia, Depok, Indonesia; ${ }^{b}$ Department of Developmental Psychology, Faculty of Psychology, Universitas Indonesia, Depok, Indonesia

*Corresponding author:

Lia Mawarsari Boediman

Department of Developmental Psychology, Faculty of Psychology, Universitas Indonesia J1. Lkr. Kampus Raya, Depok, Jawa Barat Indonesia, 16424

Tel.: +62 217270004

Email address: lia.m@ui.ac.id / Lboediman72@gmail.com 


\title{
The Effect of Perceived Maternal Acceptance-Rejection on Mental Illness among Orphaned Adolescents in Indonesia
}

\begin{abstract}
Past research has shown that orphaned adolescents who live in Indonesian orphanages are at a higher risk of experiencing various psychological disorders. In fact, parents (especially single mothers) leave their children in the orphanages because they are not able to provide adequate food, shelter, and education for their children. Despite the single mother's good intentions, the adolescent might view her actions as rejection. Adolescents who are placed in orphanages tend to have negative views of their mothers and feel they have been abandoned. Furthermore, maternal rejection has been found to be the main predictor of various forms of behavioral problems, and on the other hand, maternal acceptance has been found to have an impact on healthy social-emotional development. The aim of the present quantitative study is to examine how perceived maternal acceptance-rejection contributes to the risk of mental illness in orphaned adolescents. Participants in this study included 70 orphaned adolescents between the ages of 12 and 18 years. Parental Acceptance-Rejection questionnaire (PARQ) and youth outcome questionnaire - self report were used to collect the data. The results indicate that the higher the orphaned adolescents perceived their mother's acceptance, the lower the risk of mental illness, whereas the higher they perceived their mother's rejection, the higher the risk of mental illness. The contribution of all dimensions of rejection to mental illness was found to be $42.1 \%$. However, not all dimensions of rejection contributed significantly to mental illness, and the only dimensions found to have a significant effect were hostility/aggression and undifferentiated rejection.
\end{abstract}

Keywords - Maternal acceptance-rejection, mental illness, orphaned adolescents

\section{Introduction}

Several studies in Asia have indicated that orphaned adolescents are at a higher risk of developing mental illness. A study in Bangladesh found that $40.35 \%$ of orphaned adolescents have a prevalence of behavior and emotional disorders (Rahman et al., 2012). A study in Rajashtan, India, found that orphaned adolescents who lived in orphanages were significantly more stressed and showed lower performance in psychological wellbeing than non-orphaned adolescents (Sreekanth \& Verma, 2016). Also, a study in Dubai found that orphaned adolescents scored higher on the depression scale and have lower self-esteem than adolescents who do not live in orphanages (Asif, 2017). Adolescents have been found to face many problems in orphanages leading to depression, including caregivers who did not provide for the children's needs.

In Indonesia, a study conducted in the city of Padang found that there were adjustment-related problems in children who live in orphanages (Rahmah, Ilyas, \& Nurfahanah, 2014). The biggest adjustment problem was with peers. Adolescents tend to pick on friends while playing, find it difficult to create a fun atmosphere when they are together, and are likely to shun peers because they like to be alone (Rahmah, Ilyas, \& Nurfahanah, 2014). These findings are also in line with a study conducted by Shulga, Savchenko, and Filinkova (2016) that found that children who live in orphanages tend to lack social intelligence and social skills. Furthermore, Riyadi, Rusmil, 
and Effendi (2014) found that adolescents who live in Bandung orphanages had higher developmental problems compared with adolescents raised by their biological parents. Septiani and Utoyo (2013) also found that adolescents who lived in Jakarta orphanages had lower scores of psychological wellbeing.

On the basis of the studies above, it can be concluded that orphanages are a breeding ground for various psychiatric disorders (Mushtaq et al., 2006). Adolescents living in orphanages have poor physical health, cognitive development, and social-emotional development (Scott \& Karberg, 2016). This is because children miss their parents, experience stress due to changes in the environment, and feel the psychological impact of the stigma attached to living in an orphanage. In addition, children also lack food, cognitive stimulation, and the presence of caregivers in meeting their emotional needs (Foster et al., in Scott \& Karberg, 2016).

However, the risk of mental illness among orphaned children in Indonesia is still unknown. Considering there is a large number of orphaned children in Indonesia, this lack of research is of great concern. According to Nur Hidayat (in Sinar Harapan, 2013), the number of orphaned children in Indonesia is 3,176,642 children. The data indicated that $90 \%$ of orphaned children in Indonesia are considered paternal/maternal orphans (i.e., they still have one parent), but they live in the orphanages regardless (Save the Children, 2011). These children were sent to live in the orphanages because their remaining parent is not able to provide adequate food, shelter, and education (Tata in Republika, 2010).

Although parents might have good intentions, some of these children tend to have a negative view of the parent-child relationship (Shulga, Savchenko, \& Filinkova, 2016). The separation from their biological parents resulted in children feeling abandoned by their parents (Masterson, in Bangs, 1986). This shows a great possibility that children feel rejected by parents when they are left in the orphanage.

The decision to leave one's children in an orphanage is one of the hardest choices for parents to make (especially for single mothers). However, single mothers face economic difficulties after losing their husbands (especially if their husbands die). The Federal Interagency Forum on Child and Family Statistics found that children living with single mothers are five times poorer than children whose parents are still intact (Papalia, Old, \& Feldman, 2009). Financial problems can cause single mothers to experience acute stress, and it affects their interactions with their children, such as not paying attention to children's needs, or not concerning themselves about their growth and development (Brooks-Gunn, Duncan, \& Evans, in Papalia, Old, \& Feldman, 2009).

Single mothers who live in poverty tend to be more anxious, depressed, and easily irritated, so they become less warm, unaffectionate, and less responsive to their children (Mcloyds, in Papalia, Old, \& Feldman, 2009). Furthermore, parental warmth has been found to be an important element in children's effective developmental process (Hetherington \& Parke, in Sajid \& Riaz, 2016). Mothers who lack affection and attention make the children misinterpret their behavior as a form of rejection. Studies regarding parental acceptance-rejection have shown that 
children who feel rejection from their parents tend to have mental illness (Rohner \& Rohner, 1980; Rohner, Khaleque, \& Cournoyer, 2012). Conversely, children who feel loved and cared for tend to have higher self-esteem, social competence, and low levels of depression (Rohner \& Britner, 2002).

Parental acceptance-rejection theory (PARTheory) is an evidence-based theory of socialization and lifespan development that attempts to predict and explain major causes, consequences, and other correlates of interpersonal-especially parental-acceptance and rejection (Rohner, Khaleque, \& Cournoyer, 2012). Parental acceptance and rejection form the warmth dimension of parenting. This is a dimension or continuum on which all humans can be placed because everyone has, more or less, experienced love in childhood at the hands of primary caregivers. One end of the continuum is marked by parental acceptance, which refers to the warmth, affection, care, comfort, concern, nurturance, support, or simply love that children can experience from their parents and other caregivers. The other end of the continuum is marked by parental rejection, which refers to the absence or significant withdrawal of these feelings and behaviors, and by the presence of a variety of physically and psychologically hurtful behaviors and affects (Rohner, Khaleque, \& Cournoyer, 2012).

Parental acceptance-rejection consists of the following dimensions: warmth/affection, cold/unaffectionate, hostility/agression, indifference/neglect, and undifferentiated rejection (Rohner, 1994). The warmth/affection dimension refers to parent-child relationships where parents are perceived to give unconditional love and affection. The cold/unaffectionate dimension is the opposite of warmth/affection, both physically (lack of hugs, kisses, and caresses) and verbally (lack of praise and good words). The hostility/agression dimension refers to conditions where the child believes their parents are angry or resentful of them and intend to hurt them (physical or verbal abuse). The indifference/neglect dimension refers to conditions where the child believes their parents are unconcerned/uninterested in them. Such parents are likely to be viewed as spending a minimum amount of time with their child. The last dimension is undifferentiated rejection, which refers to the perceived absence or significant withdrawal of love and affection, but does not clearly reflect either perceived hostility/aggression or perceived indifference/neglect (Rohner, in Demetriou \& Christodoulides, 2006).

Rohner, Rohner, and Roll (1980) showed that children's perceptions of parental rejection-be it hostility/aggression, indifference/neglect, or undifferentiatedd rejection - are related to various forms of psychopathology. There is also a positive correlation between children's perceptions of low warmth/affection toward aggressive behavior, emotional instability, lack of emotional responsiveness, and low self-esteem (Rohner, Rohner, \& Roll, 1980). According to Rohner, Khaleque, and Cournoyer (2012), parental rejection is a major predictor of various forms of behavioral problems that include conduct disorders, externalizing behavior, and delinquency.

Drug and alcohol abuse has also been linked to parental rejection (Rohner, Khaleque, \& Cournoyer, 2012). Feeling rejected by parents can also lead to the development of Developmental Trauma Disorder (Van der Kolk, in Rohner, Khaleque, \& Cournoyer, 2012) and Complex Posttraumatic Stress Disorder (Courtois, in Rohner, Khaleque, \& Cournoyer, 2012). 
Individuals who feel rejected tend to feel anxious and insecure and become dependent individuals (Rohner \& Rohner, 1980). The dependent person has an intense desire to get a positive response from others and needs to be continuously convinced and given emotional support (Rohner, Khaleque, \& Cournoyer, 2012).

The rejection also makes them more hostile, aggressive, possess low self-esteem and self adequacy, and have a negative worldview (Rohner \& Rohner, 1980). As a result, they tend to be emotionally unresponsive in an effort to protect themselves from the pain of further rejection (Rohner \& Rohner, 1980; Rohner, Khaleque, \& Cournoyer, 2012). The existence of anger, negative feelings toward themselves, and other consequences of feeling rejected also reduces individuals' ability to cope with stress effectively (Rohner \& Rohner, 1980; Rohner, Khaleque, $\&$ Cournoyer, 2012).

Early adolescents are at higher risk of experiencing various forms of psychological deviations if they feel rejected by the mother (Sentse et al., 2010). The study of Sentse et al. (2010) revealed that maternal rejection (as the main attachment figure) has a more negative impact on adolescents than peer rejection. This is because a mother's acceptance is considered as something normative, whereas the mother's rejection is not. Adolescence is a period of stress and conflict (Agnew, in Sentse et al., 2010), and many psychiatric disorders occur during this period, especially for female adolescents (Fairchild, 2011).

The phenomena above show that adolescents' perception of maternal acceptance-rejection has a great impact in determining adolescents' behavior during their lifetime (Rohner, Khaleque, \& Cournoyer, 2012). Therefore, the aim of this study is to examine the effect of perceived parental warmth (especially, the mother's) on mental illness among orphaned adolescents in Indonesian orphanages. According to the findings of some of the literature cited above, orphaned adolescents were chosen as participants for the present study because they are likely to have a higher risk of mental illness than adolescents who do not live in orphanages.

The perception of parental warmth (especially, the mother's) was also chosen because the mother is conventionally seen as the main figure that gives warmth, love, and care for her children, which makes the further assumption that a mother shows greater acceptance and affection than a father. Even though studies indicate that single mothers tend to be more vulnerable to stress due to economic problems, and so have less time to give warmth and attention to their children (Brooks-Gunn, Duncan, \& Evans in Papalia, Old, \& Feldman, 2009), some are eventually forced to put their children in orphanages. The authors of the current paper thus wish to explore this phenomena of orphaned adolescents' perception about their mother's warmth and how this impacts their mental health.

This study will also identify which dimensions of parental acceptance-rejection contribute most to the development of mental illness. The research questions for the current study are the following: 
1. Does perception of maternal warmth/affection predict the risk of mental illness in orphaned adolescents?

2. Does perception of maternal coldness/unaffection, hostility/aggression, indifference/neglect, and undifferentiated rejection together predict the risk of mental illness in orphaned adolescents?

3. Does perception of maternal coldness/unaffection predict the risk of mental illness in orphaned adolescents?

4. Does perception of maternal hostility/aggression predict the risk of mental illness in orphaned adolescents?

5. Does perception of maternal indifference/neglect predict the risk of mental illness in orphaned adolescents?

Does perception of maternal undifferentiated rejection predict the risk of mental illness in orphaned adolescents? prescribed, although the various table text styles are provided. The formatter will need to create these components, incorporating the applicable criteria that follow.

\section{Methods}

\section{Participants}

The study included 70 orphaned adolescents between the ages of 12 and 18 . The orphans still met with their biological mother on several occasions as determined by the institution. The participants' biological mothers were single mothers of low social economic status who had sent their children to an orphanage in Cinere, Depok (hereby referred to as the $\mathrm{N}$ orphanage). The $\mathrm{N}$ orphanage was chosen because it had been experiencing issues related to behavior problems among orphaned adolescents, such as seniority among girls that was causing anxiety, truancy among boys, disobeying the rules (going out at night), lying, stealing, fighting, and quarreling. Also, some orphaned adolescents tended to be withdrawn. Thus, the participants were selected using a non-random, purposive sampling method. The entire population of orphaned adolescents in $\mathrm{N}$ orphanage was used in this study.

\section{Design}

This is a quantitative study that measures a certain variable to obtain a score (Kumar, 2010). The data were analyzed using multiple regression that could predict the contribution of some variables to other variables (Gravetter \& Wallnau, 2013; Kerlinger \& Lee, 2000). This study also included survey methods. According to Kerlinger and Lee (2000), survey methods are studies conducted on large or small populations by selecting and studying samples from the population to find relative incidence, distribution, and correlation between sociological and psychological variables.

\section{Instruments}

\section{1) The parental acceptance rejection questionnaire (PARQ)}

The PARQ is a 60-item self-report questionnaire designed to assess both children and adults' perceptions of parental acceptance and rejection. An important characteristic of the instrument is its phenomenological orientation in that the PARQ asks children to interpret caregiver's 
behavior through their own personal and cultural lenses. The PARQ consists of four scales: warmth/affection (20 items), hostility/aggression (15 items), indifference/neglect (15 items), and undifferentiatedd rejection (10 items) (Rohner \& Cournoyer, 1994). Individuals respond to statements on a 4-point Likert scale ranging from almost always true to almost never true. Some example of the items includes my mother talks to me in a warm and loving way (item of warmth/affection), my mother treats me harshly (item of hostility/aggression), my mother ignores me as long as I do not do anything to bother her (item of indifference/neglect), and my mother does not really love me (item of undifferentiated rejection). A total (composite) score for the PARQ, which provides an overall acceptance-rejection profile, was obtained by adding the four scales (after reverse scoring the warmth/affection scale) in order to produce a measure of parental coldness and low affection (Rohner \& Cournoyer, 1994). Demetriou and Christodoulides (2006) expanded Rohner's research by scoring each dimension of the PARQ measuring device in order for it to be multidimensional. The results of the reliability and validity of each dimension PARQ in the sample of Indonesian people (especially, adolescents on the island of Java) are warmth/affection (reliability 0,868, validity 0,436), cold/unaffectionate (reliability 0,772, validity 0,406), hostility/aggression (reliability 0,754, validity 0,383), indifference/neglect (reliability 0,740 , validity 0,344 ), undifferentiated rejection (reliability $0,721$, validity 0,436$)$.

\section{2) Youth outcome questionnaire - self report (YOQ-SR)}

Y-OQ-SR is a 64-item self-report questionnaire for adolescents aged 12 to 18 years. The YOQ-SR consists of six subscales designed to assess several behavioral domains of children and adolescents experiencing behavioral difficulties and yields a total distress score plus subscale scores for the following domains: intrapersonal distress (e.g., anxiety, depression, and hopelessness; 18 items); somatic complaints (e.g., headaches, dizziness, and stomachaches; 8 items); interpersonal relations (e.g., arguing, defiance, and communication problems; 10 items); social problems (e.g., delinquent or aggressive behaviors; 8 items); behavioral dysfunction (e.g., organization, concentration, handling frustration, and ADHD-related symptoms; 11 items); and critical items (symptoms often found in youth receiving inpatient services, such as paranoid ideation, hallucinations, mania, and suicidal feelings; 9 items) (Ridge, Warren, Burlingame, Wells, \& Tumblin, 2009).

The measure takes approximately $7 \mathrm{~min}$ to complete. Items are presented in a 5-point scale with options including 0 (never), 1 (rarely), 2 (sometimes), 3 (frequently), and 4 (almost always). Seven of the items are written and reverse scored to describe elements of healthy behavior and are weighted differently, with scores ranging from 2 to -2 . Norms for community and clinical samples (including outpatient, residential, and partial hospitalization) are provided by the test authors (Ridge, Warren, Burlingame, Wells, \& Tumblin, 2009). The results of the reliability and validity of Y-OQ-SR in the sample of Indonesian people (especially, adolescents in Java) were 0.888 and 0.341 , respectively. 


\section{Results}

The first hypothesis was that maternal warmth/affection could impact the mental illness of orphaned adolescents in the $\mathrm{N}$ orphanage. The results show that the warmth/affection dimension had a significant effect on mental illness $(\mathrm{F}=4.055, \mathrm{p}=0,048<0.05)$ and had a negative correlation with mental illness $(\beta=-0.237)$ (see Table 1). A high score on the warmth/affection thus tended to be followed by a low score on mental illness. In other words, when adolescents perceived their mother's acceptance (warmth/affection), they had a lower risk of mental illness. The first hypothesis was thus accepted.

The second hypothesis directly tested the third to sixth hypotheses that state that an effect exists with the cold/unaffectionate, hostility/aggression, indifference/neglect, and undifferentiated rejection dimensions together on the mental illness of orphaned adolescents in the $\mathrm{N}$ orphanage. The results show that the four predictor variables (rejection variables) together contributed significantly to mental illness $(\mathrm{F}=11,793, \mathrm{p}=0,000<0.05)$. This regression model contributes $42.1 \%$ in predicting mental illness (see Table 2) and $57.9 \%$ in influencing other factors. According to Cohen (in Green, 1991), the contribution of $26 \%$ is considered large, so it can be said that the contribution found in this study was able to explain many variations in mental illness. On the basis of the results, the second hypothesis was accepted.

However, not all variables in the rejection dimension contributed significantly to mental illness. Table 3 shows that the most significant variable contributing to mental illness was hostility/aggression $(\mathrm{p}<0.05)$ and undifferentiated rejection $(\mathrm{p}<0.05)$. Meanwhile, the other two variables did not contribute significantly in predicting mental illness $(p>0.05)$.

Table 3 also shows that hostility/aggression $(\beta=0.249)$ and undifferentiated rejection $(\beta=0.359)$ contributed in a positive direction. That is, if the child perceived their mother's hostility/aggression or undifferentiated rejection, then their score of mental illness was predicted to increase (i.e., the child had a higher risk of mental illness). On the basis of the results, the fourth and sixth hypotheses were accepted, whereas the third and fifth hypotheses were rejected.

The fourth hypothesis states that an effect exists between the dimensions of hostility/aggression on mental illness in orphaned adolescents in the N Orphanage. The sixth hypothesis states that there an effect exists between the dimensions of undifferentiated rejection on mental illness in orphaned adolescents in the N Orphanage. On the basis of all the hypotheses testing (dimensions of acceptance and rejection), the results obtained indicate that the first, second, fourth, and sixth hypotheses were true. Meanwhile, the third and fifth hypotheses were false. This will be explained further in the Discussion section.

The demographic data of the participants show that there were more female orphaned adolescents $(51.4 \%)$ than male $(48.6 \%)$. The majority of orphaned adolesecents were between the ages of 12 and 15 years (54.3\%) followed by 16 to 18 year olds (45.7\%). Participants who lived in the orphanage for less than 1 year $(41.43 \%)$ were the same in number as participants 
who had stayed for 1 to 3 years (41.43\%). Meanwhile, a minority of participants had lived in the orphanage for more than 3 years $(17.14 \%)$.

Table I. Coefficient Regression on Warmth/Affection

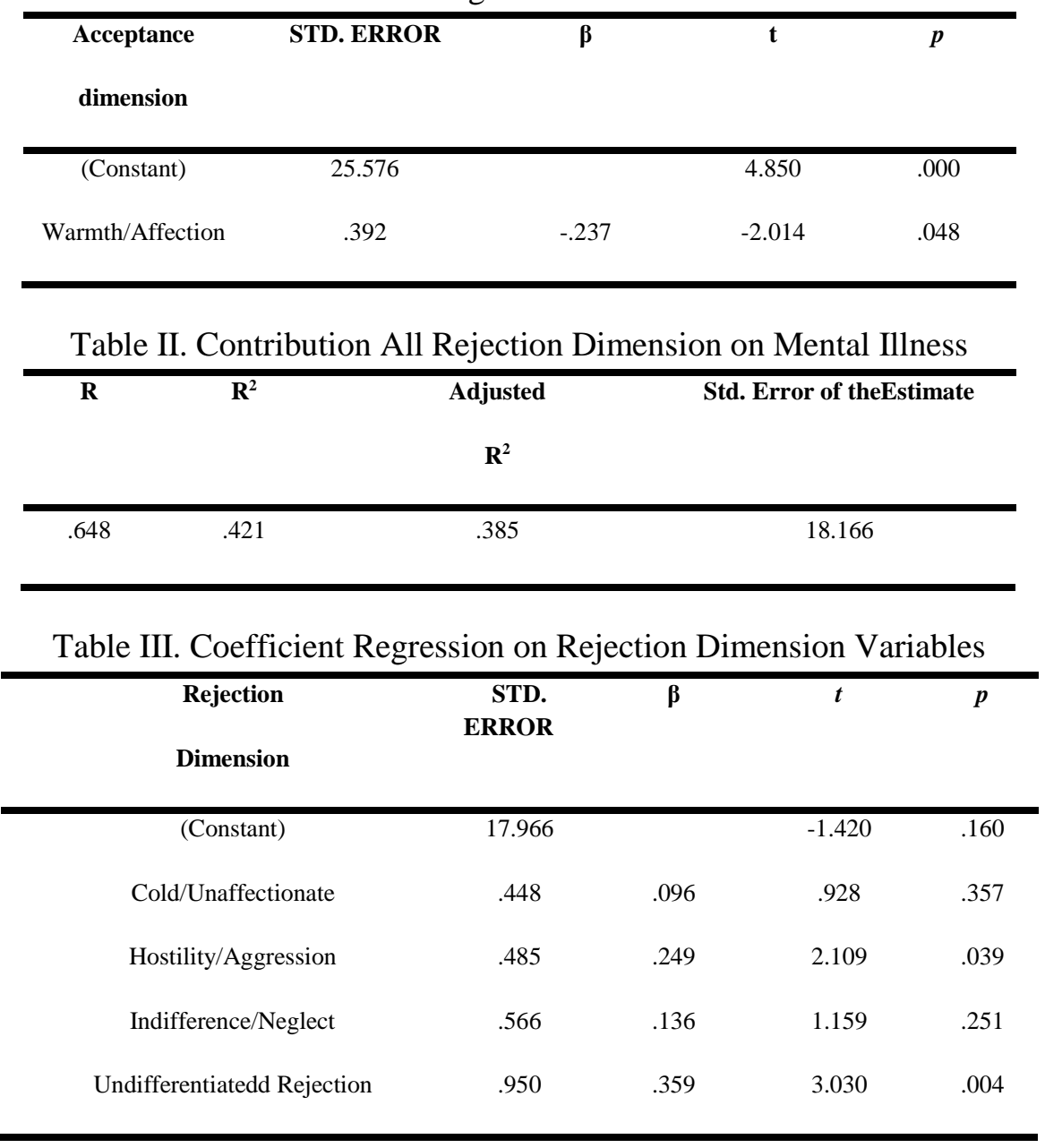

Table IV. The Demographic Data in Orphanage

\begin{tabular}{|c|c|c|c|}
\hline Characteristics & Categories & $\mathbf{N}$ & $\%$ \\
\hline \multirow[t]{2}{*}{ Gender } & Male & 34 & $48,6 \%$ \\
\hline & Female & 36 & $51,4 \%$ \\
\hline \multirow[t]{2}{*}{ Age } & $\begin{array}{c}\text { Early Adolescent (12-15 years } \\
\text { old) }\end{array}$ & 38 & $54,3 \%$ \\
\hline & $\begin{array}{l}\text { Middle Adolescent (16-18 } \\
\text { years old) }\end{array}$ & 32 & $45,7 \%$ \\
\hline \multirow{3}{*}{$\begin{array}{l}\text { Time spend in } \\
\text { the orphanage }\end{array}$} & Recently (<1 tahun) & 29 & $41,43 \%$ \\
\hline & Long enough (1-3 tahun) & 29 & $41,43 \%$ \\
\hline & Long (> 3 tahun) & 12 & $17,14 \%$ \\
\hline
\end{tabular}




\section{Discussion and Conclusion}

In general, the results of this study confirm previous studies' findings that adolescent perceptions of parental acceptance and rejection (especially the mothers') will have an impact on mental health, self-adjustment, and psychopathology (Rohner, Rohner, \& Roll, 1980; Rohner \& Britner, 2002; Rohner, Khaleque, \& Cournoyer, 2012). Orphaned adolescents who perceive acceptance (warmth and affection) from the mother will have a reduced risk of mental illness. Rohner and Britner (2002) revealed that children who feel they get love, warmth, affection, and caring from their parents will have high self-esteem, social competence, and low levels of depression and behavioral problems. The risk of psychological maladjustment in children also decreases (Rohner, Khaleque, \& Cournoyer, 2012).

In addition, a mother's warmth is also proven to increase resilience in children (Ogelman, 2015). Resilience is the ability to recover quickly after experiencing difficulties and problems (Gizir \& Aydın, in Ogelman, 2015). This proves that a mother's warmth or acceptance is an important element in creating a more effective developmental process for children (Hetherington \& Parke, in Sajid \& Riaz, 2016) where warmth is a tool needed to guide children to follow the norms and values of society (Brooks, in Sajid \& Riaz, 2016).

On the other hand, orphaned adolescents who perceived rejection from their mother had an increased risk of mental illness. Rohner, Rohner, and Roll (1980) revealed that children's perceptions of mother's rejection, both hostility/aggression, indifference/neglect, or undifferentiated rejection, are related to various forms of psychopathology, delinquency, and conduct problems. There is also a positive correlation between the child's perception of coldness/unaffection on aggression, emotional instability, lack of emotional responsiveness, low self-esteem, self-adequacy, and negative views on the world. Norton (2017) also shows that individuals who have felt their mother's rejection at important times in their development tend to have social anxiety, a high level of anxiety, and view themselves as less important/influential figures in interpersonal relationships.

However, the dimensions that contributed the most to mental illness were hostility/aggression and undifferentiated rejection. Hostility/agression refers to the conditions where the child believes their parents are angry or resentful of them and intend to hurt them (both physical and verbal abuse). Bangs (1986) found that adolescents who feel this way will tend to have feelings of hostility and behave aggressively or passively-aggressively toward others. This also makes the adolescents vulnerable to violence such as fighting and quarreling.

Adolescents who perceive maternal hostility/aggression tend to have mothers with cruel characteristics, both physically and psychologically (Hoffman, Paris, \& Hall, 1994). Rohner and Rohner (1980) found that the more mothers did not want their children, the more children tend to be mistreated. Unwanted children were more likely to be mistreated both physically and emotionally than desired children (Rohner \& Rohner, 1980). However, in addition to these fairly extreme views, there are other views that explain the behavior of mothers who tend to be rude to children. Dornbusch and Gray (in Hoffman, Paris, \& Hall, 1994) revealed that $60 \%$ of 
children headed by mother, lives below the poverty level. Mcloyd (in Papalia, Old, \& Feldman, 2009) said that single mothers who live in poverty tend to be more anxious, depressed, and easily upset with children. This allows the mother to unconsciously treat the adolesecnts rudely, which impacts the child's heart and feelings.

The other dimension that also proved to have a significant contribution to the development of mental illness among orphaned adolescents in the $\mathrm{N}$ orphanage was undifferentiated rejection. Undifferentiated rejection refers to the perceived absence or significant withdrawal of love and affection, but does not clearly reflect either perceived hostility/aggression or perceived indifference/neglect (Rohner, in Demetriou \& Christodoulides, 2006). This concept is in line with attachment theory and, more precisely, resistant/ambivalent attachment.

Resistant/ambivalent attachment is one type of attachment style that is caused by parents who do not consistently provide children with their needs. Sometimes, mothers are responsive and warm to their children, but at other times they become unresponsive and reject them. This makes children confused and unable to predict their mother's behavior (Hoffman, Paris, and Hall, 1994). Rohner and Rohner (1980) revealed that the consistency of mothers in responding to children's needs was more important than the amount of time that mothers and children spend together. Children who spend more time with their mothers than with other caregivers does not provide a basis for predicting that mothers will accept or reject them more (Rohner \& Rohner, 1980). However, the consistency of the mother in responding to the needs of the child will affect the behavior of the child in the future. There is a positive correlation between maternal attitudes that are inconsistent with psychological disorder (Dwairy, 2008). Parental inconsistency is an important factor that can increase the risk of mental illness in children (Dwairy, 2008).

There are several factors that can lead parents (especially single mothers) to be inconsistent in showing love and affection for their children. According to Rohner and Rohner (1980), the composition or number of family members in the household influences the mother's rejection. Mothers tend to feel frustrated if they are alone with their children in the household (especially if there are many young children) and a tendency to reject children as a result. Conversely, households that have alternative caregivers to help reduce the burden of care (for example, the presence of fathers), means that the mother will be more warm and loving (Rohner \& Rohner, 1980). In addition, stress due to economic conditions and fatigue after work can also make a single mother behave inconsistently with their children (Brooks-Gunn, Duncan, \& Evans, in Papalia, Old, \& Feldman, 2009).

On the other hand, the results of this study also show that two dimensions of rejection, cold/unaffectionate and indifference/neglect, had no influence on mental illness. In fact, Rohner, Rohner, and Roll (1980) revealed a positive correlation between the perception of children to coldness/unaffection with behavioral aggression, emotional instability, lack of emotional responsiveness, low self-esteem, and self-adequacy. Rohner, Rohner, and Roll (1980) also revealed the dimension of indifference/neglect along with other dimensions of rejection related to various forms of psychopathology, delinquency, and conduct problems. The absence of influence of the two dimensions of rejection above could be caused by cultural differences (in Indonesia and America specifically) in the form of behavior that reflects the acceptance and 
rejection of parents (especially mothers). This PARQ measuring instrument is also a self-report questionnaire, so there is a possibility that the participants found it difficult to express how they feel about their mother. This would be different if interviews were also conducted to confirm children's perceptions.

This study found that maternal rejection affected mental illness of orphaned adolescents in $\mathrm{N}$ orphanage by $42.1 \%$, whereas the remaining $57.9 \%$ was influenced by other factors such as temprament and self-esteem. Mesman and Koot's (2000) study shows that temperament correlates with mental illness. Temperamental withdrawal correlates with internalizing problems, whereas high levels of temperament are found to correlate with externalizing problems. Children with extreme temperaments tend to be at a higher risk for certain mental illnesses (Mesman \& Koot 2000).

Zeigler-Hill (2011) found that self-esteem is also very closely related to mental illness. High self-esteem acts as a buffer from negative experiences. People with low self-esteem tend to experience more forms of mental illness because they lack these resources (i.e., feeling that they are worthy and loved). Asif (2017) shows that children who live in orphanages tend to have lower self-esteem than children who do not live in orphanages. This is a consequence of neglect, abuse, and lack of food in orphanage institutions (Juffer, Marinus, and Ijzendoorna, in Asif, 2017).

On the other hand, the parenting style in orphanages also plays an important role in influencing the risk of mental illness. Havewala (2012) revealed that parenting styles that are democratic are highly correlated with reduced distress and pathology symptoms, whereas authoritarian parenting correlates with distress and pathology symptoms. Temperament, self-esteem, and the parenting style of foster mothers can be considered as variables that should also be examined in further studies as predictors of mental illness in orphaned adolescents.

\section{References}

Akun, E. (2017). Relations among adult's remembrances of parental acceptance-rejection in childhood, selfreported psychological adjustment, and adult psychopathology. Comprehensive Psychiatry, 77, 27-37.

Ant. (2013). Anak yatim di indonesia capai 3,2 juta. http://sinarharapan.co/index.php/news/read/17078/anakyatim-di-indonesia-capai-32-juta.html. Accessed on 2013, 29 April.

Asif, A. (2017). Self esteem and depression among orphan and non-orphan children. Journal of My Psychologist Community, Dubai UAE.

Bangs, K. P. (1989). Psychopathology and perception of parental rejection in adolescent boys in group homes. Dissertation (published). The Temple University Graduate Board, Philadephia

Demetriou, L., \& Christodoulides, P. (2006). Parental acceptance-rejection in the cypriot family: A socialpsychological research on the PART/PARQ. The Cyprus Journal of Science and Technology, 5(2), 8498.

Dwairy, M. A. (2008). Parental inconsistency versus parental authoritarianism: Associations with symptoms of psychological disorder. Journal Youth Adolescence, 37(5), 616-626. DOI 10.1007/s10964-007-9169-3.

Fairchild, G. (2011). The developmental psychopathology of motivation in adolescence. Journal of Developmental Cognitive Neuroscience, 1(4), 414-429. DOI: 10.1016/j.dcn.2011.07.009. 
Gravetter, F. J., \& Wallnau, L. B. (2013). Statistics for the behavioral sciences ninth edition. Belmont: Wadsworth Cencage Learning.

Havewala, M. C. (2012). The effects of perceived parenting styles on psychopathology, attachment, self esteem, and grit in american and indian students (Doctoral dissertation). American University, Washington DC.

Hoffman, L, Paris, S, \& Hall, E. (1994). Developmental psychology today sixth edition. USA: McGraw-Hill.

Indonesia Child Care Institutions . (2011). Save the Children. Retrieved from http://resourcecentre.savethechildren.se/node/3102.

Kerlinger, F. N., \& Lee, H. B. (2000). Foundations of behavioral research fourth edition. Belmont: Cengage Learning.

Kumar, R. (2005). Research methodology: A step by step guide for beginners second edition. London : Sage Publications.

Mesman., J, \& Koot, H. M. (2000). Common and specific correlates of preadolescent internalizing and externalizing psychopathology. Journal of abnormal psychology, 109(3), 428-437. DOI: 10.1037//0021843X.109.3.428.

Mushtaq, A., Margoob, Rather, Y. H., Khan, A. Y., Singh, G. P., Malik, Y. A., Firdosi, M. M., \& Ahmad, S. A. (2006). Psychiatric disorders among children living in orphanages: Experience from Khasmir. Journal of Traumatic Stress, 13(1), S53-S55.

Norton, E. S. (2017). The relationship between the parental acceptance-rejection questionnaire (maternal form) and the psychopathic personality inventory-revised (Doctoral dissertation). Alliant International University, San Diego.

Ogelman, H. G. (2015). Predictor effect of parental acceptance-rejection levels on resilience of preschool children. Procedia-Social and Behavioral Sciences, 174, 622-628. DOI: 10.1016/j.sbspro.2015.01.592

Papalia, D. E, Olds, S. W, \& Feldman, R. D. (2009). Human development. USA: McGraw Hill.

Rahmah, S., Ilyas, A., \& Nurfarhanah. (2014). Masalah-masalah yang dialami anak panti asuhan dalam penyesuain diri dengan lingkungan. Konselor, 3(3). ISSN 1412-9760.

Rahman, W. R., Mullick, M. S. I., Pathan, M. A. S., Chowdhury, N. F., Shahidullah, M., Ahmed, H., Roy, S., Mazumder, A. H., \& Rahman, F. (2012) Prevalence of behavioral and emotional disorders among the orphans and factors associated with these disorders. BSMMU J, 5(1), 29-34.

Restri, P. (2010). Waduh mayoritas anak di panti asuhan punya orang tua. Retrieved from https://www.republika.co.id/berita/breaking-news/nasional/10/12/16/152513-waduh-mayoritas-anakdi-panti-asuhan-punya-orang-tua.

Ridge, N. W., Warren, J. S., Burlingame, G. M., Wells, M. G., \& Tumblin, K. M. (2009) Reliability and validity of the youth outcome questionnaire self report. Journal of Clinical Psychology, 65(10), 1115-1126. DOI: 10.1002/jclp.20620.

Riyadi. R. K., \& Effendi, S. H. (2014). Risiko masalah perkembangan dan mental emosional anak yang diasuh di panti asuhan dibandingkan dengan diasuh orang tua kandung. $M K B, 46(2), 118-124$.

Rohner, E.C., Rohner, R.P., \& Roll, S. (1980). Perceived parental acceptance-rejection and children's reported behavioral dispositions: A comparative and intracultural study of american and mexican children. Journal of Cross-Cultural Psychology, 11(2), 213-231.

Rohner, R. P. (1994). Patterns of parenting: The warmth dimension in worldwide perspective. Chapter 16. Retrieved from https://www.researchgate.net/publication/255709456

Rohner, R. P., \& Britner, P. A. (2002). Worldwide mental health correlates of parental acceptance-rejection: Review of cross-cultural and intracultural evidence. Cross-Cultural Research, 36(1), 16-47.

Rohner, R. P., \& Cournoyer, D. E. (1994). Universals in youth's perceptions of parental acceptance and rejection: Evidence from factor analyses within eight sociocultural groups worldwide. Cross-Cultural Research, 28(4), 371-383.

Rohner, R. P., \& Rohner, E.C. (1980). Antecedents and consequences of parental rejection: A theory of emotional abuse. Child Abuse and Neglect, 4(3), 189-198. DOI: 0145-2134/80/1030189-10102.00/0.

Rohner, R. P., Khaleque, A., \& Cournoyer, D. E. (2012). Introduction to parental acceptance-rejection theory, methods, evidence, and implications. Journal of Family Theory \& Review, 2(1), 73-87.

Sajid, B., \& Riaz, M. N. (2016). Perceived parental rejection and psychosocial maladjustment: A study of convicts. Journal of Behavioral Science, 26(2), 39. 
Scott, M. E., \& Karberg, E. (2016). Measuring children's care arrangements and their educational and health outcomes internationally. Global Social Welfare, 3(2), 75-89. DOI 10.1007/s40609-016-0059-z.

Sentse, M., Lindenberg, S., Omvlee, A., Ormel, J., Veenstra, R. (2010). Rejection and acceptance across contexts : Parents and peers as risks and buffers for early adolescent psychopathology. Journal of Abnormal Child Psychology, 38(1), 119-130. DOI 10.1007/s10802-009-9351-z.

Septiani, N., \& Utoyo, D. B. (2013). Gambaran psychological well-being pada remaja yang tinggal di panti asuhan (Undergraduate mini thesis). Universitas Indonesia, Depok.

Shulga, T. I., Savchenko, D. D., Filinkova, E. B. (2016). Psychological characteristics of adolescents orphans with different experience of living in a family. International journal of environmental and science education, 11(17), 10493-10504.

Sreekanth, S., \& Verma, V. B. (2016). Comparative study of psychological well-being and stress among orphans and normal adolescence. International Education and Research Journal, 2(5), 114-115, E-ISSN: 24549916.

Zeigler-Hill, V. (2011). The connections between self esteem and psychopathology. Journal of Contemporary Psychotherapy, 41(3), 157-164. DOI: 10.1007//s10879-010-9167-8. 